\title{
WILLIAMS, BERNARD. VERGÜENZA Y NECESIDAD: RECUPERACIÓN DE ALGUNOS CONCEPTOS MORALES DE LA GRECIA ANTIGUA. TRAD. ALBA MONTES SÁNCHEZ. 286 PP. MADRID, 2011: LA BALSA DE LA MEDUSA
}

Jaime de Rosas Andreu Pontificia Universidad Católica de Chile

Si bien se trata de una obra publicada en el año 1993, recién después de 19 años la destacada editorial española La balsa de la Medusa nos ha regalado al mundo hispanoparlante la traducción de una de las publicaciones capitales de Bernard Williams. El libro es en realidad una codificación de lecciones impartidas en el año 1989 en la Universidad de California en Berkeley, en las que Williams analiza diversos temas como la libertad, la justicia, las emociones y la responsabilidad a partir de las tragedias griegas. Es de particular importancia su examen acerca de varios aspectos de la teoría de la acción: proaíresis, desarrollo del carácter (héxis), proto-teoría del noûs, intención, las diferentes emociones (páthe) que modelan la estructura de la acción, entre tantos otros ítems relevantes.

El libro descansa en el objetivo de describir la realidad histórica a raíz de los autores griegos de la época clásica y contrastarlas con las concepciones de nuestras civilizaciones contemporáneas. El ejercicio reflexivo busca identificar qué pensamientos y experiencias de los antiguos son dignos de recuperar y cuáles no. Ante esa indagación, Williams comienza en vista de los prejuicios tradicionales de la modernidad: "las opiniones de los griegos son anticuadas", "están completamente superadas", "la cultura griega es arcaica". La pesquisa es todavía más espinosa en cuestiones de justicia y en juzgar con ojos modernos un supuesto "progreso moral" que nos permita "objetivamente" identificar cuáles conceptos morales de los griegos antiguos son relevantes para la reflexión contemporánea y sin incurrir en un problema de autocomprensión y autoengaño. El autor no demora en defender la capacidad de poder entender sus conceptos éticos, con prescindencia de la aceptación o rechazo individual que el lector pueda tener de la concepción de los antiguos. Dicha facilidad de comprensión es posible por la vigencia de importantes ideas y concepciones morales de los antiguos que aún sobreviven y se encuentran en nuestras consciencias morales modernas. Entre ellas aún poseemos sustantivamente las nociones de responsabilidad (moral/jurídica), intención, libertad y necesidad. Esta exploración histórica se enmarca a partir de los principales autores del género literario trágico: Homero, Esquilo, Sófocles y Eurípides. 
Se aboga por un ejercicio hermenéutico de interpretación de las relaciones humanas de la sociedad a partir de una dimensión literaria, pues a la luz de los textos poéticos se nos permite captar su situación histórica: sus relaciones sociales, creencias religiosas, necesidades, conflictos políticos y éticos. Esta analogía estética es un recurso estratégico que nos permite recuperar valores comunes y destrabar conflictos sociales. De ahí que Williams muestre el paradigmático caso de Sócrates, quien ante su inminente muerte se compara con Aquiles: "que muera yo en seguida después de haber hecho justicia al culpable, a fin de que no quede yo aquí junto a las cóncavas naves, siendo objeto de risa, inútil peso de la tierra" (Ap. 28b-d).

Formalmente el libro se divide en 6 capítulos (1: La liberación de la Antigüedad; 2: Centros de la capacidad de acción; 3: Reconocer responsabilidades; 4: Vergüenza y autonomía; 5: Identidades necesarias; 6: Posibilidad, libertad y poder) y en su parte final se incorporan 2 apéndices. La exposición de cada uno de los capítulos se enmarca en presentar y refutar 2 tesis (mitos) tradicionales que se han atribuido a la Grecia antigua:

i) Los griegos antiguos carecen de conceptos sustantivos (v.g.: culpa moral, capacidad de acción o agencia); nociones que, en cambio, nosotros disfrutamos en la modernidad.

ii) Que en el mundo griego arcaico y mágico carecen de sentido la deliberación, decisión y acción porque existe el destino inexorable, un fatalismo inmediato que inhibe e infecunda la decisión que uno adopte porque el futuro será el mismo.

Se propone demostrar que, aunque haya en las tragedias griegas un fatalismo inmediato (que un futuro determinado sucederá de todos modos), ello no significa necesariamente que los agentes pueden tomar una sola decisión concreta o mucho menos negar la existencia de esa particular decisión (p. 218). Esta lectura tradicional de que nada es imposible de cambiar porque ya está determinado por los dioses o porque los hombres no toman decisiones o no piensan por sí mismo, viene a negar la facultad de la proaíresis y la capacidad responsable de los agentes, lo que constituye un yerro sistemático en la comprensión de la literatura griega antigua. Convincentemente halla en las obras de Homero una sofisticada elaboración de una teoría de la acción en el que se adscriben razones a los agentes, esto es: actitudes proposicionales en el que se atribuyen deseos, creencias, intenciones, motivos y pensamientos.

El autor se esfuerza en mostrar que un concepto clave en la teoría de la acción en Homero es el de "intención", pese a que no existe un vocablo directo y equivalente en el griego, es posible encontrarla implícita su noción en la palabra hekon. Williams ve en este término el significado de "intencionadamente" o "deliberadamente", tal como es el ejemplo en la Ilíada cuando Diomedes le arroja 
una lanza a Dolón y falla, pero siempre tuvo la intención de fallar a propósito o deliberadamente (p. 90). Así como la teoría ética de Aristóteles se funda en la psicología y en la biología, en Homero también encontramos implícitamente una psicología que provee fundamentos éticos y nos permite interpretar las capacidades racionales de sus personajes. En esta perspectiva, los conceptos de "vergüenza" y "necesidad" exhiben el tratamiento de una teoría de la acción. En la vergüenza (aidós) se extrae un modelo psicológico que impulsa a un agente a una acción u omisión, cuyo efecto generalmente tiende al deseo de esconderse o desaparecer; pero también tiene su aspecto positivo en tanto que esa emoción contribuye a la persona a reconstruirse o mejorar (p. 150). Por ejemplo, la vergüenza provoca reacciones en mí (v.g.: sentimiento de culpa) y a veces también en otros como el grito de guerra de Néstor a sus guerreros para incentivarlos a ganar la batalla pensando en sus familiares.

Por otro lado, Williams rechaza que el concepto de "necesidad" (anangkaia) persiga una línea de acción mágica y que los seres humanos se hallen impotentes frente al destino y la suerte; esta línea de explicación comienza distinguiendo la anangkaia tuché (mala fortuna) de la simple anangkaia. En ninguna de las dos nociones se vincula la necesidad como se encuentra en la episteme (ciencia demostrativa) aristotélica, en el cual no puede ser de otro modo, tal como es en la matemática. Como indica Williams, en la antigüedad griega la esclavitud era el paradigma de mala suerte, con la salvedad de Aristóteles, quien creó una teoría sistemática a favor de la esclavitud. Pero, para los griegos en general cualquier persona podía caer en la desgracia de la esclavitud, pudiendo existir la probabilidad de que en poco tiempo se pase de ser un hombre libre a esclavo. Esta posición de que la anangkeia no se encuentra intrínsecamente vinculado con la tuché se encuentra con fuerza en Eurípides, donde el sentido de la necesidad sobrenatural es prescindible dado que los personajes revelan sus intenciones y sus emociones modelan la estructura de sus acciones. La fuerza de esta argumentación será potenciada por el tratamiento que Aristóteles sistematizó sobre este tema, principalmente en la Ética a Nicómaco: en el plano ético se rige por la contingencia y en la episteme por un dominio que no puede ser de otro modo. En este sentido, Williams refuta que las tragedias griegas nos sugieran, a través de presagios y oráculos, que la existencia de un destino predeterminado conlleve que los agentes carezcan de proaíresis y otros elementos fundamentales de una teoría de la acción, porque incluso en circunstancias fatales el ser humano al no querer adoptar una decisión le es imputable por una comisión por omisión de una acción o evento determinado.

En este sentido gira el eje de la obra, que sugiere derribar la antigua fantasía — y refrán popular — "Todo tiempo pasado fue mejor", ya pronunciado por Hesíodo en Los trabajos y los días. Williams arguye que todos estos complejos 
conceptos morales de la Grecia antigua que aún sobreviven y sustentan nuestro mundo moderno deben llevarnos a revalorizar nuestros antepasados e indagar más en sus textos literarios. En ellos abunda un inmenso acervo filosófico y moral que nos permitirá comprender de mejor modo nuestro vivir y aportar en la resolución de nuestros conflictos éticos globales. Con lo anterior, el autor no niega la evolución en la historia universal, que componen un sinfín de logros a nivel de conocimientos y reflexiones morales-éticas, es decir, reconoce expresamente que el mundo antiguo no era sublime y justo (p. 257).

En fin, se trata de un trabajo bien argumentado, con importantes referencias semánticas a palabras griegas que aparecen transliteradas y que facilitan la explicación de los conceptos morales. Sin lugar a duda, el libro renueva la importancia del valor de las tragedias griegas y nos entrega estimulantes pistas para volver a releerlas y discutirlas. La posición que ocupa este libro en la investigación de la filosofía antigua logra exceder con creces las expectativas de Williams, quien advierte en el Prefacio: “(...) no soy especialista en esta materia. Soy alguien que recibió lo que solía llamarse una educación clásica, se convirtió en filósofo, y se ha mantenido en contacto con los estudios helénicos principalmente a través del trabajo en filosofía antigua" (p. 13). A pesar de esta modesta aclaración, los aportes de Williams sobre filosofía antigua son formidables y es un hecho consumado la relevancia de su legado bibliográfico tanto para los scholars y para las demás áreas filosóficas que no se mantienen dentro de los límites de los clásicos. 